\title{
When Women Deliver at Home Without a Skilled Birth Attendant: A Qualitative Study on the Role of Health Care Systems in the Increasing Home Births Among Rural Women in Southwestern Uganda
}

This article was published in the following Dove Press journal:

International Journal of Women's Health

\author{
Esther C Atukunda $\mathbb{D}^{\prime}$ \\ Godfrey R Mugyenyi ${ }^{1}$ \\ Celestino Obua (D) \\ Angella Musiimenta ${ }^{2}$ \\ Josephine N Najjuma' \\ Edgar Agaba' \\ Norma C Ware ${ }^{3}$ \\ Lynn T Matthews ${ }^{4,5}$
}

'Faculty of Medicine, Mbarara University of Science and Technology, Mbarara, Uganda; ${ }^{2}$ Faculty of Computing and Informatics, Mbarara University of Science and Technology, Mbarara, Uganda; ${ }^{3}$ Global Health and Social Medicine, Harvard Medical School, Boston, MA, USA; ${ }^{4}$ Division of Infectious Diseases and Center for Global Health, Massachusetts General Hospital, Boston, MA, USA; ${ }^{5}$ Division of Infectious Disease, University of Alabama at Birmingham, Birmingham, AL, USA
Correspondence: Esther C Atukunda Email estheratukunda@gmail.com
Background: Uganda's maternal mortality remains unacceptably high, with thousands of women and newborns still dying of preventable deaths from pregnancy and childbirth-related complications. Globally, Antenatal care (ANC) attendance has been associated with improved rates of skilled births. However, despite the fact that over 95\% of women in Uganda attend at least one ANC, over $30 \%$ of women still deliver at home alone, or in the presence of an unskilled birth attendant, with many choosing to come to hospital after experiencing a complication. We explored barriers to women's decisions to deliver in a health care facility among postpartum women in rural southwestern Uganda, to ultimately inform interventions aimed at improving skilled facility births. Methods: Between December 2018 and March 2019, we conducted in-depth qualitative face-to-face interviews with 30 post-partum women in rural southwestern Uganda. The purposeful sample was intended to represent women with differing experiences of pregnancy, delivery, and antenatal care. We included 15 adult women who had delivered from their homes and 15 who had delivered from a health facility in the previous 3 months. Women were recruited from 10 villages within $20 \mathrm{~km}$ of a regional referral hospital. Interviews were conducted and digitally recorded in a private setting by a trained native speaker to elicit experiences of pregnancy and birth. Translated transcripts were generated and coded. Coded data were iteratively reviewed and sorted to derive descriptive categories using an inductive content analytic approach.

Results: Regardless of where they decided to give birth, women wished to deliver in a supportive, respectful, responsive and loving environment. The data revealed six key barriers to women's decisions to deliver from a health care facility: 1) Fear of unresponsive care, fueling a fear of being neglected or abandoned while at the facility; 2) fear of embarrassment and mistreatment by health care providers; 3) low perception of risk associated with pregnancy and childbirth; 4) preferences for particular birthing positions and their outcome expectations; 5) perceived lack of privacy in public facilities; and 6) perceived poor clinical and interpersonal skills of health providers to adequately explain birthing procedures or support expectant or laboring women and their newborn.

Conclusion: Anticipation of unsupportive, unresponsive, disrespectful treatment, and a perceived lack of tolerance for simple, non-harmful traditions prevent women from delivering at health facilities. Building better interpersonal relationships between patients and providers within health systems could reinforce trust, improve patient-provider interaction, and facilitate useful information transfer during ANC and delivery visits. These expectations are important considerations in developing supportive health care systems that provide acceptable patient-friendly care. These findings are indicative of the vital need for midwives and other health care providers to have additional training in the role of communication and dignity in delivery of quality health care.

Keywords: childbirth, home delivery, facility delivery, health systems, barriers to care, Uganda 


\section{Introduction}

Of the estimated 300,000 women who die each year from preventable causes related to pregnancy and childbirth, over $99 \%$ occur in low- and middle-income countries. ${ }^{1-3}$ Uganda has one of the highest maternal mortality and perinatal mortality ratios in the world, with over 360 for every 100,000 women and over 40 perinatal deaths per 1000 births respectively. ${ }^{4}$

Antenatal care (ANC) prevents perinatal and maternal morbidity and mortality by promoting detection and treatment of prenatal complications, and identifying high-risk women to ensure delivery in skilled settings. ${ }^{5-9}$ ANC also provides an opportunity to support women, families, and communities at a critical time in the course of a woman's life. ${ }^{7}$ However, utilization of perinatal services in Uganda remains low. Despite the fact that over $95 \%$ of pregnant women in Uganda attend at least one ANC visit, only $58 \%$ of expectant mothers attend at least four ANC visits (of the recommended eight by WHO) and most women attend a first ANC visit at five and a half months. ${ }^{4,10}$ Although $15 \%-20 \%$ of all deliveries require emergency obstetric care, ${ }^{11,12}$ over $30 \%$ of women deliver at home alone, or in the presence of an unskilled birth attendant, with many choosing to come to hospital only after experiencing a life-threatening complication. ${ }^{4,13}$ Maternal and perinatal death rates therefore remain unacceptably high despite the Ugandan government's effort to improve access to maternity services, partly through removal of user fees.

Previous scholars have documented barriers contributing to low utilization of skilled facility services by women in low income countries as: 1) distance/inaccessibility to health facilities and or services; and/or 2) lack of adequate information on pregnancy and birth. ${ }^{14,15}$ Factors influencing women's decisions to engage in unskilled home deliveries have not been well studied. We conducted a qualitative study to identify and describe barriers to facility-based delivery on the part of pregnant women in rural southwest Uganda, to ultimately inform the development of a patient-centered intervention to improve ANC utilization and facility deliveries in Uganda.

\section{Methods}

\section{Study Design}

In this study, we used qualitative interview study design to explore and understand barriers to women's decisions and choices to deliver in a health care facility among postpartum women in rural southwestern Uganda.

\section{Study Settings}

The study was conducted between December 2018 and March 2019 in the rural southwestern Uganda's Mbarara district, one of the highest maternal mortality ratio of 489 per 100,000 women Uganda $^{16}$ with a projected dense population of 524,400, 17 sub-counties, 83 parishes and 757 villages. ${ }^{17}$ Uganda's public health system is organized into seven tiers with national and regional referral hospitals, general district hospitals and four levels of community health centers. At the county level are health center IVs (HCIV), sub-county level are health center IIIs (HCIII), the health center IIs (HCII) at the parish level and village level ( $\mathrm{HCl}$ ) that is operated by Village Health Teams (VHTs). The VHTs are community volunteers identified by their community members and are given basic training on major health programs so they can in turn mobilize and sensitize communities to actively participate in utilizing the available health services. ${ }^{18}$ According to the Uganda Ministry of Health, VHTs also act as an important link between the communities and health facilities, and can provide treatment of uncomplicated diseases like malaria, pneumonia, worm infestations, diarrhea and mass drug administration for Neglected Tropical Diseases. VHTs mobilize communities during specific health campaigns and community disease surveillance activities through active data collection and reporting. Staffing and available services vary across the four levels: HCIII and HCIV should offer Emergency Obstetrics Care (EMOC), whereas $\mathrm{HCI}$ and $\mathrm{HCII}$ serve as low resource referral units which are not able to provide EMOC and have no ambulances and blood transfusion services. ${ }^{19}$ In total, there are about 10 public facilities within a $20 \mathrm{~km}$ radius from Mbarara Regional Referral Hospital, the main teaching hospital for Mbarara University of Science and Technology. Private providers operate in parallel to the public system to provide maternal health care.

\section{Participant Sampling and Recruitment}

A purposeful qualitative sampling strategy was used to construct a sample of postpartum women with varied knowledge and experiences of pregnancy, antenatal care, and childbirth. A trained research assistant initiated contact to one of the VHTs based in each of the study villages. These VHTs in each of the 10 villages located within $20 \mathrm{~km}$ from Mbarara Regional Referral Hospital were identified from the list of VHTs provided by the district health office. The VHT contact person helped to identify women who had had their last delivery within the last 3 months. Trained research assistants then initiated a telephone contact to the identified women to seek 
permission to visit them for an interview. All women contacted were willing to participate in the study. Research assistants explained what the study is all about and obtained voluntary written informed consent from all eligible participants in the local language in a private area of their homes, communities or study office. All consenting participants gave written informed consent, or for those who could not write, a thumbprint was made on the consent form. We identified three women from each of the 10 villages with different facility or home birthing experiences. We purposively selected and recruited a total sample of 15 women who had delivered from their homes and 15 who had delivered from a health facility for their last delivery, and within the last 3 months. The places for facility or home deliveries were regardless of where their previous births happened, bringing a wide mix and range of different experiences, circumstances and decision-making processes from the participating women. Eligible women were: 1) adults of childbearing age (18-49 years); 2) had delivered a child in the previous 3 months; 3 ) had access to a mobile phone; and 4) were able and willing to give informed consent.

\section{Data Collection}

Data collection consisted of individual, open-ended interviews with each of the study participants $(\mathrm{N}=30$ interviews). A preliminary interview guide was developed and pilot tested by the primary author amongst five women in one of the 10 participating villages. The guide was revised based on the results of the pilot test. Topics included in the final version of the guide were: 1) perceptions of pregnancy and childbirth; 2) experiences of previous pregnancy or pregnancies; 3) experiences of $\mathrm{ANC}$; 4) engagement with health care providers within a facility; 5) social support; and 6) childbirth experiences. Individualized probes were used to elicit details corresponding to each topic. Field notes and observations were collected by research assistants and included in interview debriefs. As the interviews were conducted and different field notes and observations filed, emerging content was continuously reviewed by the primary and senior authors to sharpen the interview questions and identify new probes. Demographic information (eg, age, occupation, educational background) was collected usually at the outset of each interview.

All interviews took place in a private location mutually agreed upon by the participant and the interviewer. Interviews were conducted in the local language (Runyankole), and digitally recorded. Interviews lasted 60-90 minutes. Qualitative interviews were digitally recorded with the participant's permission and transcribed. A Ugandan research assistant transcribed the interviews from the local language directly to English. The research team comprised of seven senior investigators, inclusive of epidemiologists (ECA, CO), obstetrician (GRM), a medical anthropologist (NCW), maternal/reproductive health expert (LTM), nurse (JN) and a health informatics specialist (AM). Based on our previous research and work experience in maternal health in Uganda, the team sought to explore barriers for low utilization of maternity services in Uganda. Two independently hired (male and female) research assistants were trained to conduct research in human subjects. They are both social scientists. These two research assistants generated transcripts but were not involved in concept development or coding of data. This multi-disciplinary team leveraged on their expertise and experience with maternal health issues in Uganda to design, conduct, analyze and present findings from this study.

\section{Data Analysis and Interpretation}

The aim of this qualitative data analysis was to inductively construct categories describing barriers to facility-based delivery. Analysis began with repeated review of transcripts to identify relevant content. The identified content served as the basis for developing a coding scheme. Coding was done in three stages namely: 1) open coding to identify and describe women's ideas, meaningful expressions, phenomena or incidents highlighting their experiences during pregnancy and childbirth;2) axial coding to relate and label codes or data that shared concepts, dimension and properties (relationship identification); and 3) selective coding to delimit coding to the identified core variables/concepts from the data (Strauss and Corbin, 1998). Data were coded with the aid of the qualitative data management software, NVivo10 (Melbourne, Australia).

Coded data were iteratively reviewed and sorted to identify themes (repeated patterns in the data). Categories were then developed to describe each identified theme. Categories consisted of descriptive labels, elaborating text to define and specify each category's meaning, and illustrative quotes taken from the qualitative data. Data analysis was done jointly by ECA, EA, CO, JN and GRM. Both JN and ECA coded five sampled transcripts and compared the results. Together with GRM and CO, we resolved disagreements until we were satisfied with the consistency in our coding. We aimed at ensuring consistency in coding. 


\section{Results}

A total of 30 study participants with differing experiences of pregnancy and antenatal care; 15 women who delivered from their homes and 15 who delivered from a health facility were purposively selected from the 10 villages within $20 \mathrm{~km}$ from of a referral hospital with the help of existing village health teams and interviewed (Table 1). Median age was 26 years (interquartile range (IQR) $[\mathrm{IQR}] 20-33)$. Twelve women (40\%) had completed education beyond primary school. More than half (53\%) women reported household income of at least 100,000 Ugandan shillings per month. Most women (60\%) reported attending at least two ANC visits and $40 \%$ were in formal/legal partnerships. Median time since delivery was 41 (IQR: 23, 65) days. More than half of the referent pregnancies were unplanned. All women reported at least one pregnancy preceding the referent birth, with median parity of 3 (IQR: 2,4). Many women in south western Uganda would definitely like to deliver from home $(\mathrm{N}=9,30 \%)$ or facility $(\mathrm{N}=10,33.3 \%)$ in future. Four women (13.3\%) delivered from home but would not do it again. Two (6.7\%) women preferred facility delivery and reported their last home delivery as accidental. Notably, 5 (16.7\%) delivered from facility but were unsure or definitely sure of not doing so in future.

\section{Qualitative Results}

Regardless of where women decided to give birth, all of the women (30) wished to deliver in a supportive, respectful, responsive and loving environment. All women independently chose or were encouraged by their peers to deliver from a location they trusted to offer them a good birthing experience, where they would be helped unconditionally, and be treated with dignity within a friendly and private environment. Our qualitative data revealed six key and repetitive barriers to women's choices to not deliver from a facility: 1) perceived unresponsive quality of care, fueling a fear of being neglected or abandoned while at the facility; 2) fear of embarrassment and mistreatment by health care providers; 3) perceived lack of privacy in public facilities; 4) individual's perception of risk associated with pregnancy and childbirth; 5) preferred birthing positions and outcome expectations; and 6) perceived poor clinical and interpersonal skills on the part of health providers to adequately explain birthing procedures or support expectant or laboring women and their newborn. The personal desire for privacy, support and mutual respect generally seemed to greatly influence women's trust and
Table I Demographic Characteristics of Participants

\begin{tabular}{|c|c|}
\hline Characteristic & $\begin{array}{l}\text { Study } \\
\text { Participants } \\
(n=30)\end{array}$ \\
\hline $\begin{array}{l}\text { Median age, Median (Inter Quartile Range/IQR) } \\
\text { Partner age, Median (IQR) } \\
\text { Education Level, n (\%) } \\
\text { >Primary } \\
\text { SPrimary } \\
\text { None }\end{array}$ & $\begin{array}{l}26(20,33) \\
31(24,45) \\
12(40.0) \\
13(43.3) \\
5(16.7)\end{array}$ \\
\hline $\begin{array}{l}\text { Median parity (IQR) } \\
\text { Able to read English or Runyankole } \\
\text { Regular income (yes) } \\
\text { Household income } \geq 100,000 \text { Ugandan shillings/ } \\
\text { month } \\
\text { Married/legal partnership } \\
\text { Known HIV status } \\
\text { Most recent pregnancy planned }\end{array}$ & $\begin{array}{l}3(2,4) \\
25(83.3) \\
8(26.7) \\
16(53.3) \\
12(40) \\
20(66.7) \\
13(43.3)\end{array}$ \\
\hline $\begin{array}{l}\text { ANC visits } \\
0 \\
1 \\
2-3 \\
\geq 4\end{array}$ & $\begin{array}{l}3(10.0) \\
9(30.0) \\
I 1(36.7) \\
7(23.3)\end{array}$ \\
\hline $\begin{array}{l}\text { Median time since last delivery, (IQR) } \\
\text { Median number of people providing participant } \\
\text { any kind of social support (IQR) } \\
\text { Choices for Delivery } \\
\text { Would definitely like to deliver from home in future } \\
\text { Delivered from home but would not do it again } \\
\text { Preferred facility delivery but reported their last } \\
\text { home delivery as accidental } \\
\text { Delivered from facility and would like to do so in future } \\
\text { Delivered from facility but unsure if they would go again } \\
\text { Delivered from facility but would not do it in future }\end{array}$ & $\begin{array}{l}9(30.0) \\
4(13.3) \\
2(6.7) \\
10(33.3) \\
3(10.0) \\
2(6.7)\end{array}$ \\
\hline
\end{tabular}

perception of the quality of care provided at a health facility. Each barrier is described in more detail below.

\section{Perceived Unresponsive Quality of Care}

Women who believed facility personnel were unsupportive and or unresponsive to their needs were inclined to prefer home delivery. Such fears mainly seemed to evolve from women's previous individual birthing experiences or interpersonal shared birthing experiences from other women. Expectations of unresponsive care often fueled a fear of being neglected or abandoned while at the facility, causing many women to opt to stay away especially if they felt they had nothing to "tip" some health care providers to attend to them quickly. According to a 32-year-old mother of three whose last delivery was from home: 
"I think every woman would love to deliver their baby surrounded by loved ones or like by someone that supports, helps and encourages you. Or at least someone who understands and respects you .... I delivered my first born at hospital but I was not helped at all. I was just left there. Other women helped me deliver ... Personally, I have since delivered from here (home) and my friend has always responded quickly and delivered me well without problems when she is available." (Home delivery participant)

A 28-year-old mother of three said:

"I was mistreated when I delivered my first born. The midwife just abandoned me there with a lot of pain as she hurled many insults at me... It was my first time so I didn't know what to do. I was very scared to talk to her so I delivered on my own, like a goat, with everyone in the ward watching me helplessly. I almost bled to death ... That midwife was very unfriendly to everyone and didn't care. It was my worst experience ... I decided to deliver my next two babies at home and with my mama (village TBA), she is always there and treats me well. She is patient with us (women) and checks on you often ... she often comes and advises me as a daughter, which is good. I feel I do not have to be abandoned and insulted by the midwives at that centre ever again." (Home delivery participant)

A 30-year-old mother of two added:

"She (TBA) charges very little for gloves and a mackintosh. She stays close by and explains to you everything ... I can walk there to deliver without anything because she can lend me the gloves and I pay later when I get the money ... at the facility, no one will touch you without gloves or money for a tip, gauze and new clothes. The midwives will just shout at you in public and just ignore you to go through your pain until you deliver by yourself ... She will not touch you. They keep ignoring you even after moving for a long distance to reach the center. They just don't care.” (Health facility delivery participant)

A 26-year-old mother of two also said:

"I know that people in the hospital ask for tips so as to attend to you quickly ... I saw some people who delivered in this facility at our parish and ended up delivering by themselves unassisted because the midwife was in her room sleeping. My friend, I witnessed a mother die because she was not attended to on time. She just bled to death, just like that. Me I was helped by other women to deliver as there was no one to help ... The first time I thought I had no money and well, I thought I didn't need anything to deliver from here (home) except myself ... I now prefer here (TBA's home) because she helped me out a lot and treats people well. You can also pay her very little money for buying gloves and other things later as and when you get some little money and its close to home." (Health facility delivery participant)

\section{Fear of Embarrassment and Mistreatment by Health Care Providers}

After pregnant women interacted with their peers, friends or family about an unpleasant delivery experience at the health facility, the availability of alternative delivery support or option within their communities seemed to actively shape decisions to deliberately deliver from home as their first choice, and facility delivery as an alternative in case they feared embarrassment and mistreatment by health care providers. The unpleasant individual past interface with the health facility, worsened by a lack of self-esteem and financial barriers to seeking alternative private services, encouraged women to seek alternative home birth options within their communities. A 30-year-old mother of two said:

"I started my labor on my way from the farm, with my mother-in-law and husband. I just took a boda boda to a health centre nearby ... I found this midwife who just looked at me and continued minding her business on her phone behind a big desk. I went up to her to ask for help as my waters had broken ... she just swung up, and started hurling insults at me for being in her face and for appearing like a mad woman. I felt so helpless and embarrassed in front of my husband, mother-in-law and others ... Later, the midwife asked my mother-in-law to hold up my legs the whole time during delivery as other people passed by and watched. I still feel ashamed and embarrassed to this day ... For my second birth, I would have delivered from home but my friend took me to a very good midwife friend of hers in town because I don't joke with pregnancy. Even my husband was happy because she really cared for us." (Health facility delivery participant)

Women who were poorly prepared for birth often dreaded seeking care at facilities because they feared health care providers would reprimand, embarrass or unfairly judge them. These women tended to opt for the "friendly" home birth. According to a 34-year-old mother of three:

"I only went to that facility once to obtain an ANC visit card because if you don't have one in the event that you get a problem and you want to go to hospital, you will be abused, reprimanded, embarrassed, chased or can even be left there by yourself ... it's like that (ANC) card is the passport to get to be attended to by anyone at the center and that is not fair." (Home delivery participant) 


\section{A 27-year-old mother of three added:}

"My mother had given me some medicine to tie around my waist so I can deliver well and in time without problems ... The midwife saw it and shouted, insulted and embarrassed me, ripping it off like I had some bomb around my waist ... It was harmless but I was treated as a criminal. I felt sad, as if no one wanted to touch me or my baby so I kept in my bed until I was discharged ... This time, I delivered from my house. My friend's sister, who helps deliver some women in my village helped me. She made me feel okay." (Home delivery participant)

A 29-year-old mother of two also added:

"I think that midwife at that Centre was trained to abuse and just embarrass people ... We cannot all be the same. We have our different challenges. For example, if my pubic area is not shaven, must she yell and embarrass me in the whole open ward, or ignore me and not attend to me? ... they scold people for failing to shave off pubic hair in front of other women and staff. Those people make you feel small in front of all people there ... Or like if I have no new baby clothes, some people have reasons you know. I mean I just had a few items I could afford, from my previous births ... I felt so sad and embarrassed. I think women choose to stay away to avoid being shamed and embarrassed this way ... Women in this village nicknamed that midwife Y. Women stay away if they know she is the one on duty." (Health facility delivery participant)

\section{Perceived Lack of Privacy in Public Facilities}

Women's descriptions of their intimate parts being rudely and publicly exposed in front of others, with midwives offensively instructing their caretakers to hold their legs above their head on a delivery bed placed in an open area as a routine practice, left them feeling "embarrassed" and "ashamed." Women were thereafter unsure of how their significant-others perceived them as sexual partners especially since culturally, men never ordinarily see women's genital areas. Moreover, they felt physically and emotionally insecure around their caretakers, who in most cases were their immediate relatives. This discomfort after being literally exposed lingered on well way after delivery. These experiences crushed their confidence, especially after a difficult birth. The desire to have a good experience and trusting someone to support and not shame them was key to birth location choices. These choices in most cases hinged on individual's or other peoples' experiences within the community or at a certain health facility. A 27year-old mother of four said:

"All these health centers and hospitals have no private area to deliver from. We just deliver from the general wards or a labor ward packed with other different people, young and old. No privacy at all ... The midwives unleash your privates in public, with people looking on, shout at you and embarrass you if like you haven't like shaved, showered or not cooperating on the birth bed ... No one is a professor at these things you know, and there's no privacy at all. You just get embarrassed. That experience is just horrible ... it just crushes you and just buries like your confidence for good.” (Home delivery participant)

Another 25-year-old mother of two also added:

\begin{abstract}
"Me, I can never go to deliver from that health center. I am better off spending my entire savings and go to a private midwife or doctor ... I have escorted my friends and sisters there and oh, women are just left in the open ward pushing and yelling with no privacy at all ... Cleaners, attendants, relatives and other people pass by, watch and hear them scream helplessly ... You look and it's like embarrassing yourself yet genuinely in pain. There are no clean and private spaces for women to deliver in dignity without looking like helpless cows in front of everyone, God." (Health facility delivery participant)
\end{abstract}

\section{Individual's Perception of Risk Associated with Pregnancy and Childbirth}

Women's understanding of pregnancy and childbirth as well as their perceptions of death, risk, threat, and or their current health status influenced women's decisions to opt for skilled facility or unskilled home-based delivery. Women who had previous birth complications, bad experiences delivering at home, or an existing chronic medical condition such as HIV, hypertension or diabetes opted to deliver from skilled facilities "at any cost." However, this awareness of one's health status and the risks associated with pregnancy and childbirth seemed to be influenced by continuous interaction of women with their health care providers, especially during ANC visits. These supportive relationships seemed to play an important role in tackling women's concerns, overriding the perceived negativity and misconceptions about pregnancy and childbirth. For example, the fear of losing a child, a pregnancy or their lives and their expectations of a facility to help them deliver "safely" within their "risky" condition drove these women to engage and optimize/internalize benefits of seeking 
skilled help against all odds and challenges of these community-based health facilities. One of the 32-year-old mothers of two said:

"I have been on ARVs for some time now and I know that pregnancy and HIV are not good friends. I have heard from the midwives there that the virus could affect the baby or cause me serious problems, like reducing my body cells and I could easily get sick and die ... I also learnt that I could lose the baby or the pregnancy, or bleed to death, somehow like a wasted effort after I have been trying to get pregnant for 4 years now ... That's why I went to hospital as soon as I felt pain ... I know these people (health care providers) can be rude and all that, but at least I know they won't bear to watch me die helplessly in case I get a serious problem while giving birth, at least as long as they are there." (Health facility delivery participant)

According to a 37-year-old mother of five:

"Pregnancy is not a disease or anything and delivery is a normal occurrence ... Instead of going to that hospital again and be ridiculed, embarrassed or treated like a criminal, I can be here, do my chores peacefully and deliver all my babies normally here in my house with the help of my mother-in-law without anyone screaming at me or hurling insults at me ... After all, delivery is supposed to be a natural and happy moment for any woman receiving a new member of the family, while surrounded by people who care and love you. I didn't get that the first time I went to the main hospital so I did not go back." (Home delivery participant)

\section{Preferred Birthing Positions and Their Outcome Expectations}

Almost all women $(\mathrm{N}=24)$ expressed concern about the mode of delivery in facilities. All women preferred the squatting position as opposed to the routine delivery couch position, where women lie on their back. With the absence of delivery couch beds in many facilities, women deliver from normal flat beds or floor. Women expressed concern and fear, based on what they had been taught at home by their significant others, literature or personal or other experiences. Women saw the squatting position as easier, faster and a better birthing experience, despite being concerned that this position was not allowed in hospitals due to its inconvenience and space. The friends or TBAs in the villages on the other hand utilize this technique and give women a range of choices, enabling them to make their own decisions. According to a 32-year-old mother of four:

"For me, I prefer the squatting position, which has worked for me very well during my last two deliveries ... the first delivery took so long and I almost ended up in theatre. The midwife would tell me to hold my legs above my head as I push and really this is very uncomfortable and painful ... I think the head is closer to the floor when you squat so labor takes a short time. You like relieve your back of so much pressure and pain. I think a lot of women prefer squatting and weigh their options here and there." (Home delivery participant)

A 38-year-old mother of three added:

"You, tell your friends (clinicians) to be flexible and considerate also. Not to treat us like animals when giving birth. They just want you around on that small bed and pull your hair, arms and legs against your body, for like for 12 hours. It is so painful and tiresome ... me I ended up soiling everywhere and I was embarrassed and ended up in theatre after all that. At least I am told when women squat, they have a better experience and quicker birth. Even the baby is born quickly, without getting tired, those so many problems or something ... I intend to try it out next time." (Health facility delivery participant)

\section{Perceived Poor Clinical and Interpersonal Skills}

Poor interpersonal relationships between the expectant women and their health care providers seemed to demotivate women from seeking formal maternity care services. Women seemed to not trust health care providers perceived to be poor at clinical or interpersonal skills, for example, those providers observed or perceived to not know how to adequately explain birthing procedures or unable to support pregnant, laboring women and their newborn as expected. Some women reportedly opted to stay or run away when certain health care providers were on duty at the time these women were booked in for ANC visit or delivery. Some women also feared being subjected to "unnecessary" caesarean sections from health care providers perceived to be incompetent. Having a caesarean section was seen as a social embarrassment, reducing the chances of having more children for the family/spouse. Some women were therefore considered weaklings and unable to "bear many babies normally and naturally" as culturally required. According to a 36-year-old mother of five: 
"Sincerely some of those nurses need to be retrained on how to speak to people ... sometimes they tell you things and you wonder if they are serious. I mean I have had 5 deliveries and you are telling me lies ... like she wanted me to go for an operation in theatre the last time I was there and I refused because I knew I would make it. My baby was kicking and doing ok ... I simply escaped and delivered normally at my friend's place. I have never gone back." (Home delivery participant)

A 38-year-old mother of four said:

"People at these hospitals don't talk to us about anything when you are there. They just come, ask you to sleep up for examination, you see them writing in those files without even talking to you about what is up ... after a while, they tell you you are going to theatre, that's all. No questions, no time or otherwise they tell you the doctor will leave you and you die here ... and he like comes once in a week. I don't trust those people now. I went to that hospital and was immediately taken to theatre without being given a chance to push normally, now I can't have any more children that my husband needs and has married another wife." (Health facility delivery participant)

\section{Discussion}

We conducted a qualitative study to identify and describe barriers to facility-based delivery on the part of pregnant women in rural southwest Uganda. Regardless of where they decided to give birth, women wished to deliver in a supportive, respectful, responsive and loving environment. Qualitative data showed that the interaction and engagement of patients and their health care providers within health care systems greatly influenced individuals' understanding of childbirth, birth preparedness, their ability to evaluate risks and or birthing outcomes and trade-off health facility challenges and barriers to seek and experience a dignified skilled birth amongst these adult postpartum women. Qualitative data revealed six key repetitive barriers to women's choices and/ or decisions to deliver from a facility: 1) perceived unresponsive quality of care, fueling fear of being neglected or abandoned while at the facility 2) fear of embarrassment and mistreatment by health care providers; 3 ) perceived lack of privacy in public facilities; 4) individuals' low perception of risk associated with pregnancy and childbirth; 5) preferred birthing positions and outcome expectations; and 6) perceived poor clinical and interpersonal skills on the part of health providers to adequately explain birthing procedures or support expectant or laboring women and their newborn.
This analysis highlights the uniqueness of women's desire and pursuit to deliver in a supportive, respectful, responsive and loving environment. For some women, this friendly, private environment, where they feel wanted and accepted increased a sense of comfort and trust, for their handlers to take charge of their delivery, surrounded by friends and their significant others. The importance of understanding women's individual need for trust, acceptance, privacy and friendly care as key strategies to improving the quality of birth experiences and health care utilization is not surprising. Previous studies have outlined people's need to have a good, private, dignified and consented experience, free of abandonment, discrimination, abusive and disrespectful care within institutional care provisions. ${ }^{20-24}$ According to other scholars, satisfaction was the most common measure of individual's health care experience. $^{25,26}$

Women perceived maternity care from formal facilities as unresponsive, with perceived possibility of abandonment or being ignored whenever in pain or in need. Our data also showed that some women stayed away from some formal facilities and opted for alternative home births in fear of "unnecessary" caesarean section whenever their labor did not progress well due to perceived inadequate care or health-care provider engagement at these facilities. Just like our study, other scholars have reported perceptions on caesarean sections in some communities as socially or culturally unacceptable and a limiting factor to how many children one was destined to have. ${ }^{27-30}$ Other women in other settings were said to stay away from hospitals for fear of "being trained on" by medical students at certain hospitals, and that surgery acceptance, appreciation and positive feedback to the community eventually improved through adequate information sharing that progressively created trust within the community. ${ }^{31}$ Previous studies have documented pregnancy and natural childbirth to often be regarded as a sign of courage, strength and endurance in some settings and therefore carried out in a private and solitary environments. ${ }^{32}$ These expectations encourage and or propel women to exercise home or natural birth as a better way to experience natural and divine birthing experience. It was also important to note that although public facilities are supposed to be free of charge, ${ }^{4}$ the frequent stock outs of some vital supplies could mask or facilitate the reported unresponsiveness or user fees asked from women by health care providers to be attended to quickly especially in instances where women or their caretakers had no funds or were poorly prepared for birth. This consistent asking 
for "tips" at health facilities to access care may have eventually lead to perceived unresponsiveness at these facilities and eventual low maternity service utilization among some women who chose to stay away and opt to deliver at home.

Perceived high quality of maternity care and experience in the health care system, including health provider support can lead to patient engagement in health care utilization, especially where women do not feel maltreatment from health care providers and user fees are exempt or affordable $22,33-35$ According to other scholars, women's perceived need for facility-based delivery is also shaped by their perception of care quality and type in health institutions and their previous birthing experience. ${ }^{23,36,37}$ Many women in our study who had had a bad birthing experience and seemed unsure of the critical benefits of facility delivery did not seek care in the available health facilities. Without much confidence, trust, fear of being embarrassed, insulted or mistreated, many women were unwilling to seek facility delivery and deliberately delivered at home or "elsewhere" away from these facilities. On the contrary, women who had a good birthing experience worked harder to ready themselves for birthing in skilled facilities, by saving or mobilizing the needed support to help them overcome several financial or social barriers to accessing the needed skilled maternity care within their communities.

Supportive relationships and engagement with a health provider through ANC and delivery affected women's awareness, discussion on birth goals, preparedness as well as understanding and internalization of benefits of skilled delivery. In our study, women were motivated to engage with their health providers, mainly dependent on providers' clinical and interpersonal skills and relationships. Previous studies have reported that the strained health facility/provider relationship including perceived or actual discrimination, accelerates negative maternity experience, patient disengagement from health care and thus low rates of health seeking especially in facilities where providers are reportedly rude, unwelcoming or authoritarian. ${ }^{32,38,39}$ The positive interpersonal interactions and relationships during $\mathrm{ANC}$ on the other hand has been documented to provide an opportunity to discuss birth/care goals, support, educate and motivate women, families, and communities at a critical time in the course of a woman's life, including birth preparedness and tackling important concerns that debunk misconceptions about pregnancy and birth, promote detection and treatment of prenatal complications and identifying social problems and high-risk women to ensure delivery in skilled settings. ${ }^{5-9,40}$ Data from our study showed that this consistent engagement in ANC and at a time of delivery enabled women to comply, understand, internalize, prepare and take charge of their birth processes and birth decisions, which improved their pregnancy and maternity care experiences. Previous studies have also argued that this health facility birth engagement by either or both couple has potential to reduce all the three phases of delays to access skilled care; delay in decision-making to seek health care, delay in reaching a health facility and delay in obtaining appropriate care upon reaching the health facility. ${ }^{31,38,41,42}$ These delays can also be substantially reduced through involvement of social networks to support and mobilize resources for health care. ${ }^{7}$

According to Moshi and Nyamhangal, ${ }^{38}$ low risk perception of pregnancy and childbirth interfered with use of skilled birth attendants directly, as women become negligent and take risks by delivering at home, or indirectly through influencing poor or limited resource mobilization needed for facility birth. Our data revealed that women had varied perceptions about pregnancy and childbirth, as well as death, risk and threat that seemed to influence their decision to choose skilled facility or unskilled home-based delivery. The lack of active support from such important social networks such as health providers has also previously been documented to affect individuals ability to sustainably overcome many structural, psychological and social barriers to utilize and or adhere to such scheduled routine care goals. ${ }^{43,44}$ In other studies, an individual's decision to seek particular care was influenced by sharing health information within their networks, on their perceived health care quality, risks, benefits-to-care through evaluation of previous care at similar locations and their willingness to recommend a certain location or facility to others that previously offered them or their significant others a good experience. ${ }^{45-47}$

This study was one of the first attempts to understand the contribution of health care systems compared to unskilled home deliveries in Uganda. The study documents women's experiences, perceptions and choices of home-based vs skilled facility delivery amongst recent postpartum women in southwestern Uganda. This analysis can inform the design and implementation of patientcentered interventions that reinforce trust, social support, respectful care and women's birthing experiences within health facilities. This data can also inform interventions aimed at improving women's engagement/interaction with their health providers to increase uptake of ANC and facility-based delivery services in an area with relatively low utilization. This study also has some limitations, as it utilized only qualitative methods and purposive selection 
of the study sample. This approach allows for limited generalization of study findings. However, like most qualitative studies, the goal of this study was not to generalize but rather to provide a deeper contextualized understanding of the rationale and choices for home-based vs skilled facility delivery amongst recent postpartum birth parents in southwestern Uganda.

\section{Conclusion}

It is important to understand the extent to which anticipation of unsupportive, unresponsive, disrespectful treatment, and a perceived lack of tolerance for simple, non-harmful traditions prevent women from delivering at health facilities. Definitive study outcomes of such unfriendly health care systems and negative childbirth experiences will need to be evaluated within the context of stagnating maternal mortality rates in Uganda. This study also highlights the critical importance of building better interpersonal relationships between patients and providers within health systems that could facilitate useful information transfer and motivate women to deliberately and promptly make decisions aimed at seeking and experiencing a dignified skilled birthing facility with a preferred birth companion. Active and adequate engagement of women and their social networks through health education and awareness should therefore emphasize risks of pregnancy and childbirth, the benefits of skilled delivery and the uniqueness of each pregnancy and childbirth, where an emergency situation or obstetric complication can happen anytime unexpectedly. There is also a crucial need for health systems to reinforce trust, social support and positive perceptions of respectful care to improve the quality of women's birthing experiences and perceived need within maternity care provision. These findings are therefore indicative of the vital need for midwives and other health care providers to have additional training in the role of communication and dignity in delivery of quality health care. Although birthing kits and information is expected to be provided to all women during ANC visits to prepare them for birth in advance, a complementary one-on-one structured counselling session at the point of delivery could go a long way to help expectant women feel calm, safe, connected, supported and welcome at their various health facility delivery points.

\section{Abbreviations}

ANC, Antenatal Care; VHT, Village Health Team; HC, Health Center.

\section{Data Sharing Statement}

All interview guides developed specifically for use in this study are available. The original transcripts from which this data was analyzed and conclusions drawn are readily available. No identifying/confidential patient data will be shared.

\section{Ethics Approval and Consent Statement}

All study participants provided written informed consent before study enrolment. Consent to collect and publish data was obtained both verbally and in writing from all the study participants. Permission to conduct the study was obtained from district and local community leaders. The study was reviewed and approved by the Mbarara University of Science and Technology Institutional Ethics Review Committee and the Uganda National Council for Science and Technology, Kampala, Uganda. The study was conducted in accordance with the Declaration of Helsinki.

\section{Acknowledgments}

Eunice Atuhairwe, the study midwife for conducting the interviews, the VHTs and HC in charge of Biharwe, Bwizibwera, Mwizi, Katete, Kakoba, Kamukuzi, Bubaare and Kakiika.

\section{Author Contributions}

All authors made substantial contributions to conception and design, acquisition of data, or analysis and interpretation of data; took part in drafting the article or revising it critically for important intellectual content; gave final approval of the version to be published; and agree to be accountable for all aspects of the work. Lynn T Mathews and Norma C Ware are both senior authors.

\section{Disclosure}

The authors report no conflicts of interest in this work.

\section{References}

1. WHO. Maternal Mortality: Key Facts. Geneva: World Health Organisation; 2017.

2. Lawn JE, Blencowe H, Waiswa P, et al. Stillbirths: rates, risk factors, and acceleration towards 2030. Lancet. 2016;387(10018):587-603. doi:10.1016/S0140-6736(15)00837-5

3. Lawn JE, Kinney M. Preterm birth: now the leading cause of child death worldwide. Sci Transl Med. 2014;6(263):263ed221. doi:10.1126/ scitranslmed.aaa2563 
4. ICF. UBoSUa. Uganda Demographic and Health Survey 2016: Key Indicators Report. Kampala, Uganda: UBOS, and Rockville, Maryland, USA: UBOS and ICF; 2017.

5. Campbell OM, Graham WJ. Lancet maternal survival series steering G. Strategies for reducing maternal mortality: getting on with what works. Lancet. 2006;368(9543):1284-1299. doi:10.1016/S0140-6736(06)69381-1

6. Campbell OMR, Benova L, MacLeod D, et al. Family planning, antenatal and delivery care: cross-sectional survey evidence on levels of coverage and inequalities by public and private sector in 57 lowand middle-income countries. Trop Med Int Health. 2016;21 (4):486-503. doi:10.1111/tmi.12681

7. WHO. WHO Recommendations on Antenatal Care for a Positive Pregnancy Experience. Geneva: World Health Organisation; 2016.

8. Carroli G, Rooney C, Villar J. How effective is antenatal care in preventing maternal mortality and serious morbidity? An overview of the evidence. Paediatr Perinat Epidemiol. 2001;15(Suppl 1):1-42.

9. Sondaal SF, Browne JL, Amoakoh-Coleman M, et al. Assessing the effect of mHealth interventions in improving maternal and neonatal care in low- and middle-income countries: a systematic review. PLoS One. 2016;11(5): 0154664.

10. Kawungezi PC, AkiiBua D, Aleni C, et al. Attendance and Utilization of Antenatal Care (ANC) services: multi-center study in upcountry areas of Uganda. Open J Prev Med. 2015;5(3):132-142. doi:10.4236/ ojpm.2015.53016

11. Ameh C, Msuya S, Hofman J, Raven J, Mathai M, van den Broek N. Status of emergency obstetric care in six developing countries five years before the MDG targets for maternal and newborn health. PLoS One. 2012;7(12):e49938. doi:10.1371/journal.pone.0049938

12. Olsen O, Clausen JA. Planned hospital birth versus planned home birth. Cochrane Database Syst Rev. 2012;9:CD000352.

13. Tsegay R, Aregay A, Kidanu K, Alemayehu M, Yohannes G. Determinant factors of home delivery among women in Northern Ethiopia: a case control study. BMC Public Health. 2017;17(1):289. doi:10.1186/s12889-017-4159-1

14. Banke-Thomas OE, Banke-Thomas AO, Ameh CA. Factors influencing utilisation of maternal health services by adolescent mothers in low-and middle-income countries: a systematic review. $B M C$ Pregnancy Childbirth. 2017;17(1):65.

15. Geleto A, Chojenta C, Musa A, Loxton D. Barriers to access and utilization of emergency obstetric care at health facilities in sub-Saharan Africa: a systematic review of literature. Syst Rev 2018;7(1):183. doi:10.1186/s13643-018-0842-2

16. Uganda Statistics. Health Status and Associated Factors. Kampala, Uganda: Uganda Bureau of Statistics; 2017.

17. UBOS. MBARARA District Local Government statistical Abstract 2016/ 17. Kampala, Uganda: Uganda Bureau of Statistics;2017. Available from: https://www.mbarara.go.ug/sites/default/files/downloads/Statistical\% 20Abstract\%202017\%20Final.pdf. Accessed September 25, 2019.

18. MOH. Village Health Teams/Community Health Extension Workers. Kampala, Uganda: Ministry of Health; 2019. Available from: https:// health.go.ug/community-health-departments/vht-community-healthextension-workers. Accessed September 25.

19. Mbonye AK, Asimwe JB, Kabarangira J, Nanda G, Orinda V. Emergency obstetric care as the priority intervention to reduce maternal mortality in Uganda. Int $J$ Gynecol Obstetrics. 2007;96 (3):220-225. doi:10.1016/j.ijgo.2006.12.017

20. Freedman LP, Ramsey K, Abuya T, et al. Defining disrespect and abuse of women in childbirth: a research, policy and rights agenda. Bull World Health Organ. 2014;92(12):915-917.

21. Freedman LP, Kruk ME. Disrespect and abuse of women in childbirth: challenging the global quality and accountability agendas. Lancet. 2014;384(9948):e42-44. doi:10.1016/S0140-6736(14)60859-X

22. Moyer CA, Adongo PB, Aborigo RA, Hodgson A, Engmann CM. 'They treat you like you are not a human being': maltreatment during labour and delivery in rural northern Ghana. Midwifery. 2014;30 (2):262-268. doi:10.1016/j.midw.2013.05.006
23. Gabrysch S, Campbell OM. Still too far to walk: literature review of the determinants of delivery service use. BMC Pregnancy Childbirth. 2009;9:34.

24. Kruk ME, Kujawski S, Mbaruku G, Ramsey K, Moyo W, Freedman LP. Disrespectful and abusive treatment during facility delivery in Tanzania: a facility and community survey. Health Policy Plan. 2018;33(1):e26-e33.

25. Peca E, Sandberg J. Modeling the relationship between women's perceptions and future intention to use institutional maternity care in the Western Highlands of Guatemala. Reprod Health. 2018;15 (1):9. doi:10.1186/s12978-017-0448-5

26. Sawyer A, Ayers S, Abbott J, Gyte G, Rabe H, Duley L. Measures of satisfaction with care during labour and birth: a comparative review. $B M C$ Pregnancy Childbirth. 2013;13(1):108. doi:10.1186/1471-2393-13-108

27. Awoyinka BS, Ayinde OA, Omigbodun AO. Acceptability of caesarean delivery to antenatal patients in a tertiary health facility in south-west Nigeria. J Obstetrics Gynaecol. 2006;26(3):208-210. doi:10.1080/01443610500508311

28. Loto OM, Adewuya AO, Ajenifuja OK, et al. Cesarean section in relation to self-esteem and parenting among new mothers in southwestern Nigeria. Acta Obstet Gynecol Scand. 2010;89(1):35-38. doi:10.3109/00016340903280966

29. Loto OM, Adewuya AO, Ajenifuja OK, Orji EO, Owolabi AT, Ogunniyi SO. The effect of caesarean section on self-esteem amongst primiparous women in South-Western Nigeria: a case-control study. J Maternal-Fetal Neonatal Med. 2009;22(9):765-769. doi:10.3109/14767050902801660

30. Parkhurst JO, Rahman SA. Life saving or money wasting? Perceptions of caesarean sections among users of services in rural Bangladesh. Health Policy. 2007;80(3):392-401. doi:10.1016/j.healthpol.2006.03.015

31. Iliyasu Z, Abubakar IS, Galadanci HS, Aliyu MH. Birth preparedness, complication readiness and fathers" participation in maternity care in a northern Nigerian community. Afr J Reprod Health. 2010;14(1):21-32.

32. Kabakyenga JK, Ostergren PO, Emmelin M, Kyomuhendo P, Odberg Pettersson K. The pathway of obstructed labour as perceived by communities in south-western Uganda: a grounded theory study. Glob Health Action. 2011;4.

33. Moyer CA, Mustafa A. Drivers and deterrents of facility delivery in sub-Saharan Africa: a systematic review. Reprod Health. 2013;10:40.

34. Moyer CA, Dako-Gyeke P, Adanu RM. Facility-based delivery and maternal and early neonatal mortality in sub-Saharan Africa: a regional review of the literature. Afr J Reprod Health. 2013;17(3):30-43.

35. Anastasi E, Borchert M, Campbell OM, et al. Losing women along the path to safe motherhood: why is there such a gap between women's use of antenatal care and skilled birth attendance? A mixed methods study in northern Uganda. BMC Pregnancy Childbirth. 2015;15:287.

36. Bohren MA, Hunter EC, Munthe-Kaas HM, Souza JP, Vogel JP, Gulmezoglu AM. Facilitators and barriers to facility-based delivery in low- and middle-income countries: a qualitative evidence synthesis. Reprod Health. 2014;11(1):71.

37. Gabrysch S, Nesbitt RC, Schoeps A, et al. Does facility birth reduce maternal and perinatal mortality in Brong Ahafo, Ghana? A secondary analysis using data on 119244 pregnancies from two cluster-randomised controlled trials. The Lancet Global Health. 2019;7(8):e1074-e1087. doi:10.1016/S2214-109X (19)30165-2

38. Moshi F, Nyamhanga T. Understanding the preference for homebirth; an exploration of key barriers to facility delivery in rural Tanzania. Reprod Health. 2017;14(1):132.

39. FitzGerald C, Hurst S. Implicit bias in healthcare professionals: a systematic review. BMC Med Ethics. 2017;18(1):19. doi:10.1186/ s12910-017-0179-8

40. Attanasio L, Kozhimannil KB. Health care engagement and follow-up after perceived discrimination in maternity care. Med Care. 2017;55(9):830-833. doi:10.1097/MLR.0000000000000773

41. Teela KC, Mullany LC, Lee CI, et al. Community-based delivery of maternal care in conflict-affected areas of eastern Burma: perspectives from lay maternal health workers. Soc Sci Med. 2009;68 (7):1332-1340. doi:10.1016/j.socscimed.2009.01.033 
42. Iliyasu Z, Abubakar IS, Abubakar S, Lawan UM, Gajida AU. Patients" satisfaction with services obtained from Aminu Kano Teaching Hospital, Northern Nigeria. Niger J Clin Pract. 2010;13 (4):371-378.

43. Atukunda EC, Musiimenta A, Musinguzi N, et al. Understanding patterns of social support and their relationship to an ART adherence intervention among adults in rural Southwestern Uganda. AIDS Behav. 2017;21(2):428-440. doi:10.1007/s10461-016-1559-7

44. Kim TH, Connolly JA, Tamim H. The effect of social support around pregnancy on postpartum depression among Canadian teen mothers and adult mothers in the maternity experiences survey. $B M C$ Pregnancy Childbirth. 2014;14:162.
45. Klinkenberg WD, Boslaugh S, Waterman BM, et al. Inpatients' willingness to recommend: a multilevel analysis. Health Care Manage Rev. 2011;36(4):349-358. doi:10.1097/HMR.0b013e3182104e4a

46. Tung Y-C, Chang G-M. Patient satisfaction with and recommendation of a primary care provider: associations of perceived quality and patient education. Int J Qual Health Care. 2009;21(3):206-213. doi:10.1093/intqhe/mzp006

47. Sawyer A, Rabe H, Abbott J, et al. Parents' experiences and satisfaction with care during the birth of their very preterm baby: a qualitative study. BJOG. 2013;120(5):637-643. doi:10.1111/1471-0528.12104

\section{Publish your work in this journal}

The International Journal of Women's Health is an international, peerreviewed open-access journal publishing original research, reports, editorials, reviews and commentaries on all aspects of women's healthcare including gynecology, obstetrics, and breast cancer. The manuscript management system is completely online and includes a very quick and fair peer-review system, which is all easy to use. Visit http://www.dovepress.com/testimonials.php to read real quotes from published authors. 